Bull. Chem. Soc. Ethiop. 2012, 26(3), 407-414.

Printed in Ethiopia

DOI: http://dx.doi.org/10.4314/bcse.v26i3.9

ISSN 1011-3924

(c) 2012 Chemical Society of Ethiopia

\title{
TWO Zn AND Hg BROMIDE SALTS BASED ON 1-ETHYL-3-METHYL IMIDAZOLIUM IONIC LIQUID: IONOTHERMAL SYNTHESIS, STRUCTURES AND SUPRAMOLECULAR ORGANIZATION
}

\author{
Xiu-Cheng Zhang ${ }^{*}$ and Bing $\mathrm{Liu}^{2 *}$ \\ ${ }^{1}$ College of Science, Northeast Forestry University, 150040 Harbin, Heilongjiang, P. R. China \\ ${ }^{2}$ Department of Chemistry, University of Aveiro, CICECO, 3810-193 Aveiro, Portugal
}

(Received October 14, 2011; revised July 16, 2012)

\begin{abstract}
Two $\mathrm{Zn}$ (II) and $\mathrm{Hg}$ (II) bromide salts, $\left[\mathrm{EMI}_{2}\left[\mathrm{ZnBr}_{4}\right]\right.$ (1) and $[\mathrm{EMI}]\left[\mathrm{HgBr}_{3}\right]$ (2), have been synthesized under ionothermal conditions using 1-ethyl-3-methyl imidazolium bromide ([EMI]Br) as solvents. 1 consists of tetrahedral anion $\left[\mathrm{ZnBr}_{4}\right]^{2-}$ and $\mathbf{2}$ consists of $1 \mathrm{D}$ double chain locating in the cavities surrounded by $[\mathrm{EMI}]^{+}$cations. Both compounds exhibit 3D supramolecular architectures organized by the C-H $\cdots$ Br hydrogen bondings and alkyl-alkyl interactions.
\end{abstract}

KEY WORDS: Crystal structure, 1-Ethyl-3-methyl imidazolium bromide, Ionothermal synthesis, Supramolecular organization

\section{INTRODUCTION}

In 2002, ionic liquid [BMIM] $\left[\mathrm{BF}_{4}\right]$ (BMIM = 1-butyl-3-methylimidozolium) was used as reaction media for the first time in the synthesis of metal-organic frameworks [1]. Ionothermal synthesis is now flourishing in many fields, such as nanomaterials [2-4], framework materials [5-8], organic synthesis, electrochemistry and catalysis [9-11]. The principal feature of ionothermal synthesis is that the ionic liquids (ILs) act as both the "designed" green solvents and the structure-template providers, which have demonstrated their potential in novel material discovery. ILs consist of a bulky organic cation and an inorganic/organic anion [12]. Bulky organic cations usually are quaternary ammonium, phosphonium, pyridinium, and imidazolium [13-15]. Thus ILs are somewhat similar to polar solvents, suitable for dissolving the inorganic components required for the synthesis process [16-17]. ILs have many unique properties: low melting point $\left(<100{ }^{\circ} \mathrm{C}\right)$, extremely low volatility, chemical and thermal stability, nonflammability, high ionic conductivity, high heat capacity, high thermal conductivity, and wide electrochemical potential window [18-19]. For example, negligible vapor pressure will eliminate the safety concerns associated with high self-engendered pressures and lead to the integration with microwave synthesis [20]. Compared with hydro(solvo)thermal synthesis, no other solvents added to the reaction system as space fillers, no competition in ionothermal synthesis between template-framework and solvent-framework interactions will offer significantly different reaction environment [21]. Despite the difficulties in crystallization, we used 1-ethyl-3-methyl imidazolium bromide ([EMI]Br) as starting material reacting with $\mathrm{Zn}\left(\mathrm{NO}_{3}\right)_{2} / \mathrm{Hg}\left(\mathrm{NO}_{3}\right)_{2}$ to obtain two new d ${ }^{10}$ bromide salts, $[\mathrm{EMI}]_{2}\left[\mathrm{ZnBr}_{4}\right](\mathbf{1})$ and $[\mathrm{EMI}]\left[\mathrm{HgBr}_{3}\right]$ (2). The structural features and supramolecular organizations in both bromide salts are described.

*Corresponding author. E-mail: bliu_1203@yahoo.com.cn 


\section{EXPERIMENTAL}

\section{Materials and physical measurements}

The reagents and solvents were used directly as supplied commercially without further purification except [EMI]Br. [EMI]Br was synthesized from the reaction of ethylbromide with 1-methylimidazole according to literature processes [22-23]. The IR spectra were recorded on a Nicolet Magna 750 FT-IR spectrometer with $\mathrm{KBr}$ pellet in the range $4000-400 \mathrm{~cm}^{-1}$. Elemental analyses of $\mathrm{C}, \mathrm{H}$ and $\mathrm{N}$ were carried out on a Vario EL III elemental analyzer. The melting point of [EMI]Br was measured at X-4 microscopic melting point determinator.

\section{Synthesis of 1-ethyl-3-methylimidazolium bromide}

Under inert nitrogen atmosphere conditions, $100 \mathrm{~mL}$ degassed bromoethane $(146.0 \mathrm{~g}, 1.34 \mathrm{~mol})$ was added to $35.7 \mathrm{~mL}$ redistilled 1-methylimidazole $(37.0 \mathrm{~g}, 0.45 \mathrm{~mol})$ with constant stirring. The mixture was refluxed at $40{ }^{\circ} \mathrm{C}$ for $3 \mathrm{~h}$ and then cooled to room temperature. A pale yellow oil was produced. $100 \mathrm{~mL}$ ethyl acetate was added, and the product crashed out of solution. The product was washed with ethyl acetate, and dried under a vacuum at $25{ }^{\circ} \mathrm{C}$ for one day to give 1-ethyl-3-methylimidazolium bromide as a white solid (m.p. $=80-83{ }^{\circ} \mathrm{C}$, yield: $85 \%$ ).

Synthesis of $[E M I]_{2}\left[\mathrm{ZnBr}_{4}\right](\mathbf{1}) .0 .1 \mathrm{mmol}, 29.6 \mathrm{mg} \mathrm{Zn}\left(\mathrm{NO}_{3}\right)_{2} \cdot 6 \mathrm{H}_{2} \mathrm{O}$ and $0.1 \mathrm{mmol}, 12.8 \mathrm{mg} 3-$ amino-1,2,4-triazole-5-carboxylic aid were placed in a $25 \mathrm{~mL}$ Teflon-lined stainless-steel autoclave mixed with [EMI] $\mathrm{Br}(\mathrm{ca} .1 .0 \mathrm{~g})$. The mixture was kept in a furnace at $160{ }^{\circ} \mathrm{C}$ for 5 days, and then cooled at $2{ }^{\circ} \mathrm{C} / \mathrm{h}$ to room temperature to get colorless crystals of $\mathbf{1}$ suitable for Xray diffraction. The crystals were manually selected under a microscope and used for all characterizations. Elemental analysis found (calcd) for $\mathrm{C}_{12} \mathrm{H}_{22} \mathrm{Br}_{4} \mathrm{~N}_{4} \mathrm{Zn}$ : C, 23.69 (23.73); H, 3.73 (3.65); N, 9.11 (9.23). IR data (in $\mathrm{KBr}, \mathrm{cm}^{-1}$ ) for 1: 3434(w), 3127(s), 2981(m), 1700(w), 1594(s), 1533(s), 1468(w), 1444(m), 1360(w), 1292(m), 1228(s), 1114(s), 1033(m), 950(m), 860(m), 752(m), 668(m), 624(w).

Synthesis of $[E M I]\left[\mathrm{HgBr}_{3}\right]$ (2). The reaction process of $\mathbf{2}$ is similar to that of $\mathbf{1}$ using $\mathrm{Hg}\left(\mathrm{NO}_{3}\right)_{2} \cdot \mathrm{H}_{2} \mathrm{O}(0.1 \mathrm{mmol}, 34.2 \mathrm{mg})$ replacing $\mathrm{Zn}\left(\mathrm{NO}_{3}\right)_{2} \cdot 6 \mathrm{H}_{2} \mathrm{O}$. Elemental analysis found (calcd) for $\mathrm{C}_{6} \mathrm{H}_{11} \mathrm{Br}_{3} \mathrm{HgN}_{2}$ : C, 12.89 (13.07); H, 2.11 (2.01); N, 5.11 (5.08). IR data (in $\mathrm{KBr}, \mathrm{cm}^{-1}$ ) for 2: 3430(w), 3118(s), 2938(m), 1700(w), 1594(s), 1525(s), 1468(w), 1360(w), 1249(m), 1108(s), 963(m), 852(m), 738(m), 651(m), 624(w).

\section{Structural determination and refinement}

Data collections of compounds $\mathbf{1}$ and $\mathbf{2}$ were performed on Rigaku Mercury CCD diffractometer equipped with graphite-monochromated MoK $\alpha$ radiation $(\lambda=0.71073 \AA)$. Intensity data were collected by the narrow frame method at $293 \mathrm{~K}$ and corrected for Lorentz and polarization effects as well as for absorption by the $\omega$ scan technique and were reduced using CrystalClear program [24]. The structures were solved by direct methods using SHELXTL ${ }^{\mathrm{TM}}$ package of crystallographic software and refined by full-matrix least-squares technique on $F^{2}$ [25]. All nonhydrogen atoms were refined with anisotropic thermal parameters. Hydrogen atoms attached to $\mathrm{C}$ atoms were located at geometrically calculated positions and refined with isotropic thermal parameters included in the final stage of the refinement on calculated positions bonded to their carrier atoms. Because of bad crystal quality of $\mathbf{1}$, the not so good crystal diffraction data results in a large final $w R_{2}(0.1530)$. A summary of the structural determinations and refinements for $\mathbf{1}$ and $\mathbf{2}$ is listed in Table 1. Selected bond distances and angles of $\mathbf{1}$ and $\mathbf{2}$ are shown in Table 2. 
Table 1. Crystal data and structure refinement parameters for $\mathbf{1}$ and $\mathbf{2}$.

\begin{tabular}{|c|c|c|}
\hline Parameter & 1 & 2 \\
\hline Empirical formula & $\mathrm{C}_{12} \mathrm{H}_{22} \mathrm{Br}_{4} \mathrm{~N}_{4} \mathrm{Zn}$ & $\mathrm{C}_{6} \mathrm{H}_{11} \mathrm{Br}_{3} \mathrm{HgN}_{2}$ \\
\hline Color and habit & Colorless block & Colorless prism \\
\hline Crystal size $(\mathrm{mm})$ & $0.26 \times 0.24 \times 0.24$ & $0.22 \times 0.17 \times 0.06$ \\
\hline Crystal system & Tetragonal & Orthorhombic \\
\hline Space group & $I 4_{1} / \mathrm{a}$ & $P 2_{1} 2_{1} 2_{1}$ \\
\hline$a(\AA)$ & $14.443(1)$ & $8.207(2)$ \\
\hline$b(\AA)$ & $14.443(1)$ & $9.824(2)$ \\
\hline$c(\AA)$ & $19.959(4)$ & $15.542(4)$ \\
\hline$V\left(\AA^{3}\right)$ & $4163.5(9)$ & $1253.1(5)$ \\
\hline 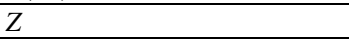 & 8 & 4 \\
\hline$F w$ & 607.35 & 551.49 \\
\hline$D_{\text {calcd }}\left(\mathrm{Mgm}^{-3}\right)$ & 1.938 & 2.923 \\
\hline$\mu\left(\mathrm{mm}^{-1}\right)$ & 8.856 & 21.807 \\
\hline$F(000)$ & 2336 & 984 \\
\hline Reflections measured & 18530 & 11590 \\
\hline Independent reflections & $2583\left(R_{\text {int }}=0.0487\right)$ & $3074\left(R_{\text {int }}=0.0425\right)$ \\
\hline Observed reflection $[I>2 \sigma(I)]$ & 1459 & 2566 \\
\hline Final $R_{1}{ }^{a}, w R_{2}{ }^{b}[I>2 \sigma(I)]$ & $0.0589,0.1530$ & $0.0286,0.0568$ \\
\hline$R_{1}^{a}, w R_{2}^{b}$ indices (all) & $0.1093,0.1817$ & $0.0417,0.0604$ \\
\hline$G O F$ on $F^{2}$ & 1.037 & 1.059 \\
\hline$(\Delta / \sigma)_{\max / \min }$ & $0.001,0.000$ & $0.018,0.001$ \\
\hline Largest difference peak $\left(\mathrm{e} \AA^{-3}\right)$ & $1.666,-0.793$ & $0.769,-1.526$ \\
\hline
\end{tabular}

$R_{1}^{a}=\left(\Sigma|| F_{o}|-| F_{c} \| / \Sigma\left|F_{o}\right|\right) \cdot w R_{2}^{b}=\left[\Sigma\left(w\left(F_{o}^{2}-F_{c}^{2}\right)^{2}\right) / \Sigma\left(w\left|F_{o}^{2}\right|^{2}\right)\right]^{1 / 2}$.

Table 2. Selected bond distances $(\AA \hat{)})$ and angles $\left({ }^{\circ}\right)$ for $\mathbf{1}$ and $\mathbf{2}$.

\begin{tabular}{|l|l|l|l|}
\hline \multicolumn{5}{|c|}{1} \\
\hline Zn1-Br1 & $2.3731(5)$ & Zn2-Br2 & $2.3740(5)$ \\
\hline Br1-Zn1-Br1A & $111.16(3)$ & Br2-Zn2-Br2E & $110.45(1)$ \\
\hline Br1-Zn1-Br1B & $108.63(1)$ & Br2-Zn2-Br2F & $107.52(3)$ \\
\hline \multicolumn{5}{|l|}{ 2 } \\
\hline Hg1-Br2 & $2.8210(8)$ & Hg1-Br1B & $3.220(1)$ \\
\hline Hg1-Br1 & $2.9017(8)$ & Hg1-Br3A & $3.1396(9)$ \\
\hline$H g 1-B r 3$ & $3.0077(9)$ & Br1-Hg1-Br3 & $89.59(3)$ \\
\hline Br1-Hg1-Br1B & $169.41(2)$ & Br2-Hg1-Br3A & $92.93(3)$ \\
\hline Br3-Hg1-Br3A & $174.70(2)$ & Br1-Hg1-Br3A & $85.26(2)$ \\
\hline Br2-Hg1-Br1 & $91.77(3)$ & Br3-Hg1-Br3A & $174.70(2)$ \\
\hline Br2-Hg1-Br3 & $88.48(3)$ & Hg1-Br3-Hg1B & $83.79(3)$ \\
\hline
\end{tabular}

Symmetry codes: 1) $A=-x+1,-y+3 / 2, z ; B=-y+5 / 4, x+1 / 4,-z+1 / 4 ; D-y+1 / 4, x+1 / 4,-z+1 / 4 ; E=y-1 / 4,-$ $\mathrm{x}+1 / 4,-\mathrm{z}+1 / 4 ; \mathrm{F}-\mathrm{x},-\mathrm{y}+1 / 2, \mathrm{z} ; 2) \mathrm{A}=\mathrm{x}+1 / 2,-\mathrm{y}-3 / 2,-\mathrm{z}-1 ; \mathrm{B}=\mathrm{x}-1 / 2,-\mathrm{y}-3 / 2,-\mathrm{z}-1$.

\section{RESULTS AND DISCUSSION}

\section{Synthesis}

The imidazolium $\mathrm{Zn}$ and $\mathrm{Hg}$ bromide salts $\mathbf{1}$ and $\mathbf{2}$ were synthesized under ionothermal conditions at $160{ }^{\circ} \mathrm{C}$ for 5 days under autogenous pressure. Unexpectedly, 3-amino-1,2,4triazole-5-carboxylic acid did not participate in the final structures. Our other series experiments 
proved that 3-amino-1,2,4-triazole-5-carboxylic acid would decompose beyond $130{ }^{\circ} \mathrm{C}$. The contrast experiment of omitting 3-amino-1,2,4-triazole-5-carboxylic acid did not yield any crystals but white powders. In our estimation, possibly, the existence and/or decomposing of 3amino-1,2,4-triazole-5-carboxylic acid can offer a suitable $\mathrm{pH}$ range, which affects the reaction and/or crystallization environments of the systems. This similar phenomena also appeared in the synthetic processes of imidazolium bromoplumbates $[\mathrm{EMI}] \mathrm{PbBr}_{3}$ and $\left[\mathrm{BMI}_{2} \mathrm{PbBr}_{4}(\mathrm{BMI}=1\right.$ buthyl-3-methylimidazolium cation) [26].

Structural description of $[E M I]_{2}\left[\mathrm{ZnBr}_{4}\right](\mathbf{1})$

Compound 1 crystallizes in the tetragonal space group $I 4_{1} / \mathrm{a}$, whose asymmetric unit comprises of two distinct $\mathrm{Zn}$ (II) atoms of a quarter occupancy, two $\mathrm{Br}^{-}$anions and a [EMI ${ }^{+}$cation (Figure 1a). Each $\mathrm{Zn}(\mathrm{II})$ atom bonds to four symmetry-related $\mathrm{Br}^{-}$anions to form a negative $\left[\mathrm{ZnBr}_{4}\right]^{2-}$ tetrahedron with $\mathrm{Zn} 1-\mathrm{Br} 1=2.3731(5), \mathrm{Zn} 2-\mathrm{Br} 2=2.3740(5) \AA$ and $\mathrm{Br}-\mathrm{Zn}-\mathrm{Br}$ angles in the ranges of 108.63(1)-111.16(3) and 107.52(3)-110.45(1) ${ }^{\circ}$ respectively (Table 2). The positive charge on $[\mathrm{EMI}]^{+}$cation is balanced by two $\left[\mathrm{ZnBr}_{4}\right]^{2-}$ units of a quarter occupancy. $[\mathrm{EMI}]^{+}$ cation exhibits weak $\mathrm{C}-\mathrm{H} \cdots \mathrm{Br}$ hydrogen bondings (C12-H12A $\cdots \mathrm{Br} 1, \mathrm{C} 14-\mathrm{H} 14 \mathrm{~A} \cdots \mathrm{Br} 2)$ through the $\mathrm{C}$ atoms in the imidazolium ring, with two separated $\mathrm{Br}^{-}$anions (Figure 1b), and alkyl-alkyl interactions (methyl-methyl: C1-H1C $\cdots$ H3B-C3; C3-H3B $\cdots$ H1A-C1; methyl-aromatic alkyl: C1$\mathrm{H} 1 \mathrm{~A} \cdots \mathrm{H} 14 \mathrm{~A}-\mathrm{C} 14 ; \mathrm{C} 2-\mathrm{H} 2 \mathrm{~A} \cdots \mathrm{H} 15 \mathrm{~A}-\mathrm{C} 15)$ (Figure 1b, Table 3). Each $\left[\mathrm{ZnBr}_{4}\right]^{2-}$ unit is surrounded by four $[\mathrm{EMI}]^{+}$cations. Through the $\mathrm{C}-\mathrm{H} \cdots \mathrm{Br}$ and and $\mathrm{C} 1-\mathrm{H} 1 \mathrm{C} \cdots \mathrm{H} 3 \mathrm{~B}-\mathrm{C} 3$ interaction, a 2D supramolecular sheet is shaped, and further connected by the rest interactions into a 3D supramolecular architecture (Figure 2a). The aforementioned alkyl-alkyl interactions lead to the formation of the channels of $6.08 \times 5.72 \AA^{2}$ with [EMI $]^{+}$as walls, which are fully occupied by $\left[\mathrm{ZnBr}_{4}\right]^{2-}$ tetrahedra (Figure $2 \mathrm{~b}$ ).

Table 3. Hydrogen bondings and alkyl-alkyl interactions in $\mathbf{1}$ and $\mathbf{2}$.

\begin{tabular}{|c|c|c|c|c|}
\hline$D-H$ & $H \cdots A$ & $D \cdots A$ & $<(D H A)$ & Interactions \\
\hline \multicolumn{5}{|c|}{1} \\
\hline 0.93 & 2.88 & $3.749(5)$ & 156.5 & C14-H14A $\cdots \mathrm{Br} 2$ \\
\hline 0.93 & 2.74 & $3.646(4)$ & 164.1 & $\mathrm{C} 12-\mathrm{H} 12 \mathrm{~A} \cdots \mathrm{Br} 1$ \\
\hline 0.96 & 3.38 & $3.829(11)$ & 110.6 & C1-H1C $\cdots$ H3B-C3 \\
\hline 0.96 & 3.05 & $3.829(11)$ & 139.2 & C3-H3B $\cdots H 1 A-C 1$ \\
\hline 0.96 & 3.35 & $3.809(8)$ & 111.3 & C1-H1A $\cdots$ H14A-C14 \\
\hline 0.97 & 2.96 & $3.838(9)$ & 151.7 & $\mathrm{C} 2-\mathrm{H} 2 \mathrm{~A} \cdots \mathrm{H} 15 \mathrm{~A}-\mathrm{C} 15$ \\
\hline \multicolumn{5}{|c|}{2} \\
\hline 0.96 & 3.04 & $3.843(8)$ & 141.7 & $\mathrm{C} 1-\mathrm{H} 1 \mathrm{~B} \cdots \mathrm{Br} 1$ \\
\hline 0.96 & 3.18 & $3.830(8)$ & 126.2 & $\mathrm{C} 1-\mathrm{H} 1 \mathrm{~A} \cdots \mathrm{Br} 2$ \\
\hline 0.97 & 3.23 & $3.857(9)$ & 123.6 & $\mathrm{C} 2-\mathrm{H} 2 \mathrm{~B} \cdots \mathrm{Br} 3$ \\
\hline 0.96 & 2.99 & $3.778(8)$ & 140.5 & $\mathrm{C} 3-\mathrm{H} 3 \mathrm{~A} \cdots \mathrm{Br} 1$ \\
\hline 0.97 & 3.06 & $3.994(11)$ & 163.4 & $\mathrm{C} 2-\mathrm{H} 2 \mathrm{~B} \cdots \mathrm{H} 1 \mathrm{~B}-\mathrm{C} 1$ \\
\hline 0.96 & 3.34 & $3.917(12)$ & 120.9 & $\mathrm{C} 3-\mathrm{H} 3 \mathrm{~B} \cdots \mathrm{H} 1 \mathrm{~B}-\mathrm{C} 1$ \\
\hline 0.96 & 3.10 & $3.866(11)$ & 138.2 & C3-H3A $\cdots$ H14A-C14 \\
\hline 0.96 & 3.11 & $3.665(12)$ & 118.3 & C3-H3A $\cdots H 15 A-C 15$ \\
\hline
\end{tabular}


(a)

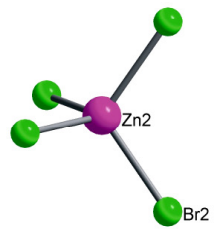

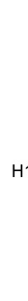

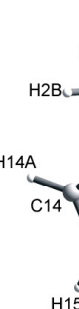

(b)

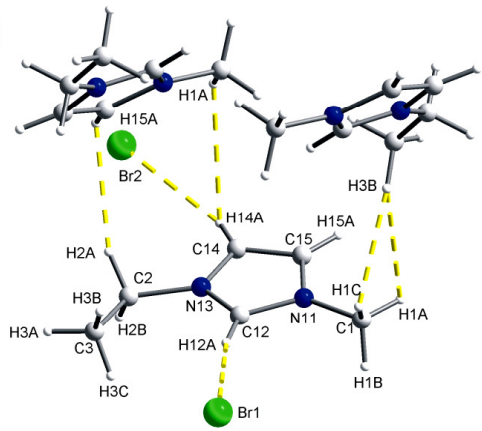

Figure 1. (a) The structural motif of 1; (b) The $\mathrm{C}-\mathrm{H} \cdots \mathrm{Br}$ hydrogen bondings and alkyl-alkyl interactions in $\mathbf{1}$.
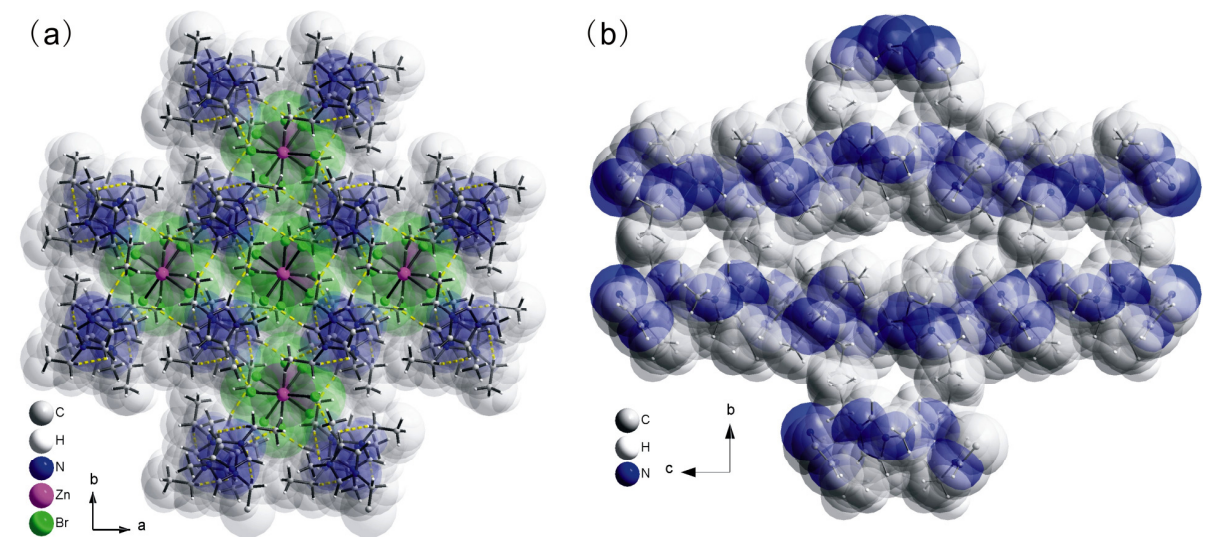

Figure 2. (a) The 3D supramolecular architecture in 1; (b) the channels along the $a$-direction in the 3D supramolecular architecture.

\section{Structural description of [EMI][HgBr $]$ (2)}

The structural analysis indicates that compound $\mathbf{2}$ features a 1D inorganic chain anchoring in the channels made up of imidazolium cations. Compound $\mathbf{2}$ crystallizes in orthorhombic chiral space group $P 22_{1} 2_{1} 2_{1}$, whose structural flack factor is -0.0445 with 1291 Friedel pairs, indicating the accuracy of its absolute structure. In its asymmetry unit, there are one $\mathrm{Hg}$ (II), three distinct $\mathrm{Br}^{-}$anions and one [EMI] ${ }^{+}$cation. Three positive charges on $\mathrm{Hg}(\mathrm{II})$ and $[\mathrm{EMI}]^{+}$cations are balanced by three $\mathrm{Br}^{-}$anions. The $\mathrm{Hg}$ (II) center is five-coordinated by five bromine atoms in a slightly distorted $\mathrm{HgBr}_{5}$ square pyramid with $\mathrm{Br} 1, \mathrm{Br} 3$ and their symmetry-related $\mathrm{Br} 1 \mathrm{~B}$ and $\mathrm{Br} 3 \mathrm{~A}$ atoms $(A=0.5+x,-1.5-y,-1-z ; B=x-0.5,-1.5-y,-1-z)$ shaping the basal plane and $\mathrm{Br} 2$ occupying the apex. The maximum deviation of $\mathrm{Hg} 1$ is $0.0939 \AA$ from the best least-square basal plane built by $\mathrm{Br} 1, \mathrm{Br} 1 \mathrm{~B}, \mathrm{Br} 3$ and $\mathrm{Br} 3 \mathrm{~A}$ atoms. The $\mathrm{HgBr}_{5}$ square pyramid displays $\tau=$ $0.0882[\tau=(\beta-\alpha) / 60$, where $\alpha$ and $\beta$ are the two biggest bond angles around $\mathrm{Hg}(\mathrm{II})$ center; $\tau=0$ for ideal square pyramid; and $\tau=1$ for ideal trigonal bipyramid] [27]. All $\mathrm{Hg}-\mathrm{Br}$ distances range in 2.8210(8)-3.220(1) $\AA$, which are within the van der Waals contact limits (Table 2). Br1 and 
Br3 adopt $\mu_{2}$-mode linking neighboring $\mathrm{Hg}$ (II) centers into a double zigzag chain, in which a $\mathrm{HgBr}_{5}$ square pyramid shares two edges with neighboring two $\mathrm{HgBr}_{5}$ square pyramids (Figure 3a). Similarly, there exist $\mathrm{C}-\mathrm{H} \cdots \mathrm{Br}$ hydrogen bondings $(\mathrm{C} 1-\mathrm{H} 1 \mathrm{~B} \cdots \mathrm{Br} 1$; $\mathrm{C} 1-\mathrm{H} 1 \mathrm{~A} \cdots \mathrm{Br} 2$; $\mathrm{C} 2-$ $\mathrm{H} 2 \mathrm{~B} \cdots \mathrm{Br} 3$; $\mathrm{C} 3-\mathrm{H} 3 \mathrm{~A} \cdots \mathrm{Br} 1$ ) between alkyl and three distinct $\mathrm{Br}^{-}$anions (Figure 3a). Through

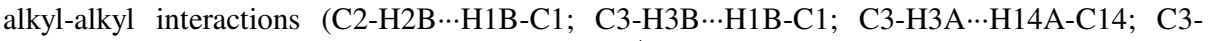
$\mathrm{H} 3 \mathrm{~A} \cdots \mathrm{H} 15 \mathrm{~A}-\mathrm{C} 15)$ between neighboring $[\mathrm{EMI}]^{+}$cations (Figure 3b, Table 3), the 3D supramolecular architecture is formed and further stabilized (Figure 4a). The 1D double chains are surrounded by $[\mathrm{EMI}]^{+}$cations, thus to form channels of $5.90 \times 5.75 \AA^{2}$ with $[\mathrm{EMI}]^{+}$cations as walls, which are fully occupied by the 1D chains (Figure 4b).
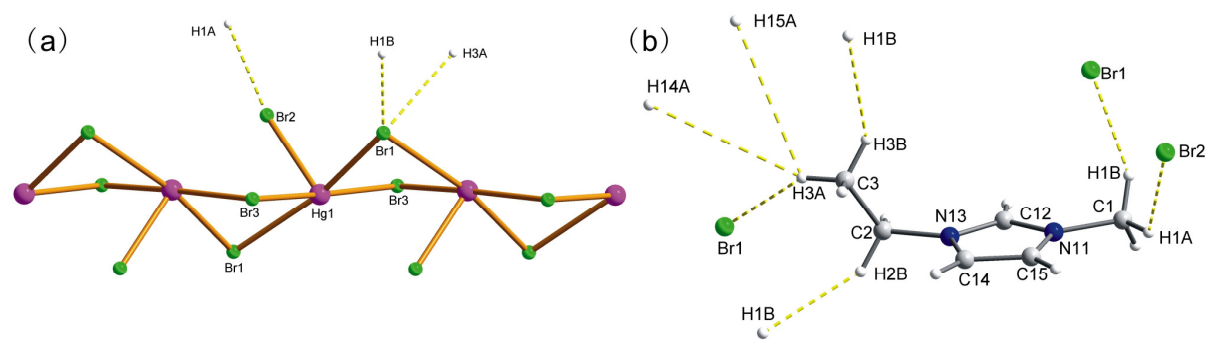

Figure 3. (a) $1 \mathrm{D}\left[\mathrm{HgBr}_{5}\right]$ chain and its hydrogen bondings between $\mathrm{EMI}^{+}$and $\mathrm{Br}^{\square}$ in 2; (b) The $\mathrm{C}-\mathrm{H} \cdots \mathrm{Br}$ hydrogen bondings and alkyl-alkyl interactions in $\mathbf{2}$.
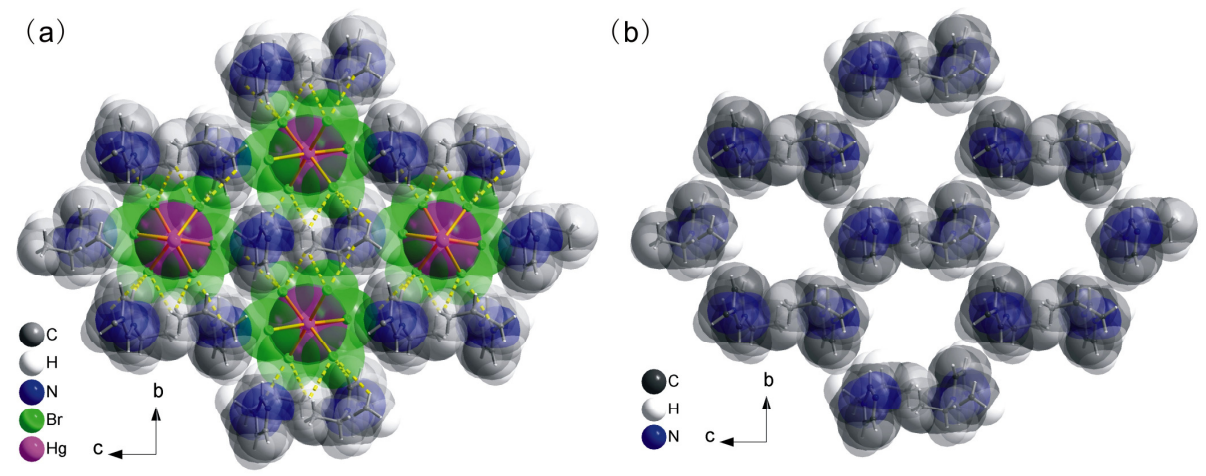

Figure 4. (a) The 3D supramolecular architecture in 2; (b) the channels along the $a$-direction in the 3D supramolecular architecture.

Compounds 1 and $\mathbf{2}$ were obtained from similar ionothermal processes and derived from the same $[\mathrm{EMI}] \mathrm{Br}$ ionic liquid. Compound $\mathbf{1}$ is to some degree like the reported [bpyr] $\left[\mathrm{AlCl}_{4}\right]$ (bpyr = 1-butylpyridinium) [26] and Compound 2 has the same structure as [EMI] $\mathrm{PbBr}_{3}$ [26], but contains richer interactions. Observing this type of the compounds [26, 28, 29-32], we can find a phenomenon that [organic cation] $\mathrm{X}(\mathrm{X}=$ halide or halide-containing anions) reacts with metal salts, specially the metal halides, $\mathrm{X}^{-}$tends to change into larger metal-containing polyatomic anion. This can be demonstrated in the compounds in this work and those reported in the literatures $[26,31,32]$. For example, $[\mathrm{Im}] \mathrm{Cl}$ with $\mathrm{FeCl}_{3}$ can produce $[\mathrm{Im}]\left[\mathrm{FeCl}_{4}\right](\mathrm{Im}=$ imidazolium) [32], [bpyr] $\left[\mathrm{AlCl}_{4}\right]$ with $\mathrm{V}_{2} \mathrm{O}_{5}$ to be [bpyr $]_{4}\left[\mathrm{~V}_{4} \mathrm{O}_{4} \mathrm{Cl}_{12}\right]$ [28] and [EMI][ $\left.\mathrm{AlCl}_{4}\right]$ with 
$\mathrm{KZr}_{6} \mathrm{CCl}_{15}$ to be $[\mathrm{EMI}]_{4}\left[\mathrm{Zr}_{6} \mathrm{CCl}_{18}\right]$ [33]. The larger anions should be possible to promote the structural stability with the presence of the large organic cations. The metal-containing anions play a key role in the formations of the final 3D supramolecular architectures of $\mathbf{1}, \mathbf{2}$ and $[\mathrm{EMI}] \mathrm{PbBr}_{3}$ [26]. The anions result in the difference in the hydrogen bondings between the inorganic blocks and $[\mathrm{EMI}]^{+}$cations. Compound $\mathbf{1}$ has only two types of $\mathrm{C}-\mathrm{H} \cdots \mathrm{Br}$ hydrogen bondings per $[\mathrm{EMI}]^{+}$, both through the alkyl group in the imidazolium ring, none from the alkyl group of side chains. While in 2 , more $\mathrm{C}-\mathrm{H} \cdots \mathrm{Br}$ hydrogen bondings exist around $[\mathrm{EMI}]^{+}$; contrarily, all four types of $\mathrm{C}-\mathrm{H} \cdots \mathrm{Br}$ hydrogen bondings appear through the alkyl side chains, none from imidazolium ring. The alkyl-alkyl interactions in both compounds are very similar, showing little effect of anions on the [EMI ${ }^{+}$itself. More interactions also induce the difference in sizes of cavities. The cavities in $\mathbf{2}$ are supposed to be bigger than those in $\mathbf{1}$, due to the bigger inorganic anions. Actually, the cavities in $\mathbf{1}$ are a little larger than those in $\mathbf{2}$, which reasonably relates with the interactions.

\section{CONCLUSIONS}

Our attempt in the investigation of alkyl-imidazolium ILs produced two $\mathrm{d}^{10}$ dialkylimidazolium bromide salts, $\left[\mathrm{EMI}_{2}\left[\mathrm{ZnBr}_{4}\right]\right.$ (1) and $[\mathrm{EMI}]\left[\mathrm{HgBr}_{3}\right]$ (2), from ionothermal reactions with 1ethyl-3-methyl imidazolium bromide as solvents. 1 consists of tetrahedral anion $\left[\mathrm{ZnBr}_{4}\right]^{2-}$ and $\mathbf{2}$ consists of $1 \mathrm{D}$ double chain, both locating in the cavities surrounded by $[\mathrm{EMI}]^{+}$cations. Compounds 1 and $\mathbf{2}$ are 3D supramolecular architectures based on the connections of $\mathrm{C}-\mathrm{H} \cdots \mathrm{Br}$ and alkyl-alkyl interactions. The structural analysis in $\mathrm{C}-\mathrm{H} \cdots \mathrm{Br}$ and alkyl-alkyl interactions, and cavity sizes suggests the anions in $\mathbf{1}$ and $\mathbf{2}$ play an important role in their 3D supramolecular structures.

\section{SUPPLEMENTARY}

Crystallographic data for the structure reported here has been deposited with the Cambridge Crystallographic Data Centre (Deposition No. CCDC: 824348-824349). That data can be obtained free of charge via http://www.ccdc.cam.ac.uk/perl/catreq.cgi (or from the CCDC, 12 Union Road, Cambridge CB2 1EZ, UK; fax: +44 1223 336033; e-mail: deposit@ccdc.cam.ac.uk).

\section{ACKNOWLEDGEMENTS}

The authors gratefully acknowledge the financial support of the NSF of Heilongiiang Province (B2000714) and the Dissertation Funds for the Graduate Students of Northeast Forestry University (GRAM09).

\section{REFERENCES}

1. Jin, K.; Huang, X.; Pang, L.; Li, J.; Appel, A.; Wherland, S. Chem. Commun. 2002, 2872.

2. Antonietti, M.; Kuang, D.; Smarsly, B.; Zhou, Y. Angew. Chem., Int. Ed. 2004, 43, 4988.

3. Biswas, K.; Rao, C.N.R. Chem. Eur. J. 2007, 13, 6123.

4. Itoh, H.; Naka, K.; Chujo, Y. J. Am. Chem. Soc. 2004, 126, 3026.

5. Cooper, E.R.; Andrews, C.D.; Wheatley, P.S.; Webb, P.B.; Wormald, P.; Morris, R.E. Nature 2004, 30, 1012.

6. Parnham, E.R.; Morris, R.E. Acc. Chem. Res. 2007, 40, 1005.

7. Xu, L.; Yan, S.H.; Choi, E.Y.; Lee, J.Y.; Kwon. Y.U. Chem. Commun. 2009, 3431.

8. Xu, L.; Choi, E.Y.; Kwon. Y.U. Inorg. Chem. 2008, 47, 1907.

9. Ohno, H. Electrochemical Aspects of Ionic Liquids, Wiley-Interscience: New York; 2005. 
10. Lancaster, M. Green Chemistry: An Introductory Text, The Royal Society of Chemistry: Cambridge, UK; 2002.

11. Pârvulescu, V.I.; Hardacre, C. Chem. Rev. 2007, 107, 2615.

12. Wasserscheid, P.; Welton, T. Ionic Liquids in Synthesis, Wiley-VCH: Weinehim, Germany; 2003.

13. Visser, A.E.; Swatloski, R.P.; Reichert, W.M.; Griffin, S.Y.; Rogers, R.D. Ind, Eng. Chem. Res. 2000, 39, 3596.

14. Hussey, G. L. Pure Appl. Chem. 1998, 60, 1763.

15. Ito, Y.; Nohira, T. Electrochim. Acta. 2000, 45, 2611.

16. Huddleston, J.G.; Visser, A.E.; Reichert, W.M.; Willauer, H.D.; Broker, G.A.; Rogers, R.D. Green Chem. 2001, 3, 156.

17. Welton, T. Coord. Chem. Rev. 2004, 248, 2459.

18. Seddon, K.R. J. Chem. Technol. Biotechnol. 1997, 68, 351.

19. Seddon, K.R. Chem. Eng. 2002, 730, 33.

20. Lin, Z.; Wragg, D.S.; Morris, R.E. Chem. Commun. 2006, 2021.

21. Cooper, E.R.; Andrews, C.D.; Wheatley, P.S.; Webb, P.B.; Wormald, P.; Morris, R.E. Stud. Surf. Sci. Catal., A 2005, 158, 247.

22. Parnham, E.R.; Morris, R.E. Chem. Mater. 2006, 18, 4882.

23. Bonhote, P.; Dias, A.P.; Papageorgiou, N.; Kalyanasundaram, K.; Cratzel, M. Inorg. Chem. 1996, 35, 1168.

24. Rigaku, CrystalClear 1.3.6, Software User's Guide for the Rigaku. R-Axis, Mercury and Jupiter CCD Automated X-ray Imaging System, Rigaku Molecular Structure Corporation: Utah, USA; 2002.

25. Siemens, SHELXTLTM Version 5 Reference Manual, Siemens Engergy \& Automation Inc.: Madison, Wisconsin, USA; 1994.

26. Thirumurugan, C.; Rao, C.N.R. Cryst. Growth Des. 2008, 8, 1640.

27. Addision, A.W.; Rao, T.N.; Reedijk, J.; Riju, J.V.; Verschoor, G.C. J. Chem. Soc., Dalton Trans. 1984, 1349.

28. Mahjoor, P.; Latturner, S.E.; Cryst. Growth Des. 2009, 9, 1385.

29. Ding, J.; Wu, J.; MacFarlane, D.R.; Price, W.E.; Wallace, G. Phys. Chem. Chem. Phys. 2008, $10,5863$.

30. Endres, F.; El Abedin, S.Z.; Saad, A.Y.; Moustafa, E.M.; Borissenko, N.; Price, W.E.; Wallace, G.G.; MacFarlane, D.R.; Newman, P.J.; Bund, A. Phys. Chem. Chem. Phys. 2008, $10,2189$.

31. Babai, A.; Mudring, A.V.Z. Anorg. Allg. Chem. 2006, 632, 1956.

32. Lin, I.J.B.; Vasam, C.S. J. Organomet. Chem. 2005, 690, 3498.

33. Sun, D.; Hughbanks, T. Inorg. Chem. 2000, 39, 1964. 